Abbott, W. E., Kreiger, H., Holden, W. J., Bradshaw, J. \& Levy, S. (1957). Metabolism 6, 69r. Caldwell, F. T. (1962). Ann. Surg. 155, i19.

Campbell, R. M. \& Cuthbertson, D. P. (I967). Q. Fl exp. Physiol. 52, i14.

Cuthbertson, D. P., Smith, C. M. \& Tilstone, W. J. (ro68). Br. F. Surg. 55, 513.

Rose, W. C. (1949). Fedn Proc. Fedn Am. Socs exp. Biol. 8, 546.

Van Itallie, T. B., Waddell, W. R., Geyer, R. P. \& Stare, F. J. (r952). Archs intern. Med. 89, 353.

Wilmore, D. W., Groff, D. B., Bishop, H. C. \& Dudrick, S. J. (1969). F. Paediat. Surg. 4, $18 \mathrm{r}$.

\title{
Feeding the unconscious patient
}

\section{By Sally Day and Monamy Buckell*, Atkinson Morley's Hospital, Neurosurgical Unit, St George's Hospital, London, $S W_{\mathrm{I}}$}

This communication deals with the feeding of unconscious patients from the point of view of the hospital dietitian, and describes the choice, organization and assessment of tube feeds. The observations are the result of close collaboration between a dietitian and a chemical pathologist working with the neurosurgical unit of Atkinson Morley's Hospital where tube feeding is an important part of the total care of the unconscious patient.

There are forty-six adult and nine paediatric beds, and a quick turnover of cases with a high proportion of acutely-ill, comatose patients. In this situation the dietitian is called upon to provide feeds that will cover the patient's maintenance requirements and repair the deficits, also taking into account the problems peculiar to cerebral damage and the unconscious state. These patients are even more dependent than babies, they cannot cry when they are starving or thirsty or have a headache, and, in addition, their homoeostatic mechanisms may have broken down so that the fluid and electrolyte content of their feeds becomes a critical matter.

The advantages of nasogastric feeding are listed in Table $\mathrm{I}$. In terms of total calories, and of carbohydrate, protein and fat we can give a complete diet and supplements of iron and vitamins can be easily added as appropriate. When absorption from the gut is satisfactory, fluid balance can usually be controlled via the feeds. However, when fluid and electrolyte balance is critical, intravenous therapy may be needed in addition.

\section{Table 1. Advantages of nasogastric tube feeding}

1. Nutritional requirements covered

2. Drugs, electrolytes and nutritional supplements given via nasogastric tube

3. Generally well tolerated and easily modified

4. Ease of preparation, storage and administration

5. Very low cost in comparison with intravenous preparations available

*Present address: The Maudsley Hospital, Denmark Hill, London SE5. 
In most patients this method of feeding is well tolerated, and even if difficulty is encountered to begin with, the patient's gut can usually be coaxed back into action by the use of a carefully graded scheme. The mixture used must be designed so that its composition can be easily modified when this is indicated either by its nonacceptance by the gut or by the finding of abnormal blood chemistry. Cost is very favourable when compared with the intravenous route.

Administration of tube feeds is a skilled nursing procedure. It appears to be insufficiently taught except in the specialized units. With a good routine and full co-operation between doctor, nurse and dietitian, the disadvantages listed in Table 2 can be avoided.

Table 2. Special considerations in tube feeding the comatose patient



There is the danger of pulmonary aspiration because the patient cannot swallow to make sure the feed goes down to his stomach. Sometimes he cannot even cough to defend his lungs if the feed is 'going down the wrong way'. It is vital to check that the tube is in the stomach before each feed is given. Dehydration may be present on admission or may develop due to inadequate fluid with feeds or, in our neurosurgical practice, following infusions of mannitol or urea to lower intracranial pressure. There may be depressed absorption where the stomach has remained empty for some time. However, as mentioned earlier, we find that this is not a major problem if small dilute feeds are used to begin with. Deranged metabolism can arise from the reaction to injury or from localized brain damage destroying the homoeostatic mechanisms that control water and electrolytes, i.e. sodium, potassium and chlorine. Diminished renal function with reduced urinary output and raised blood urea may indicate the need for a lower protein level to be prescribed. Diarrhoea can be a problem at times, but it is usually manageable by altering the composition of the feeds.

Turning to the composition of the feed; we want to give sufficient calories and protein to prevent or minimize further loss and make good any deficit that has already arisen. The importance of giving an adequate calorie:nitrogen ratio (Cuthbertson \& Tilstone, 1969) and how this can be achieved with tube feeding will be explained later. There must be an adequate supply of minerals and vitamins and enough water for the excretion of all the non-metabolized part of the diet, together with any additional waste produced by tissue breakdown. As a fair guide $30 \mathrm{ml}$ of fluid $/ \mathrm{kg}$ body-weight should be allowed over $24 \mathrm{~h}$. Water will also have to 
be supplied to cover non-renal losses. The feeding schedule must be designed to allow for easy increase or decrease of total calories, protein, water or sodium.

Various approaches have been made to the provision of these requirements. Some workers have recommended that each meal should be served on the ward, then homogenized and blended with fluid and given as a nasogastric tube feed. This, however, in practice has not proved satisfactory. Others have reconstructed their own feeds using eggs, milk, milk powder, soya flour and a large number of other ingredients. It is possible in this way to produce an ideal feed, but it is too time-consuming and complicated where there are any number of patients to serve. We therefore come to what is available commercially (Fig. I).

\begin{tabular}{|c|c|c|c|c|c|c|}
\hline & Complan & $\begin{array}{c}\text { Modified } \\
\text { Complan } \\
\text { (AMH } \\
\text { s.t) }\end{array}$ & $\begin{array}{c}\text { Modified } \\
\text { Complan } \\
\text { (low- } \\
\text { protein) }\end{array}$ & Forceval & $\mathrm{ClBF}$ & Nutrament \\
\hline $\begin{array}{l}\text { Percentage } \\
\text { source of } \\
\text { calories }\end{array}$ & VIIII & & & & & \\
\hline $\begin{array}{l}\text { Non-protein energy } \\
(\mathrm{kcal} / \mathrm{g} \mathrm{N})\end{array}$ & $6 \%$ & 126 & 253 & 113 & 113 & 100 \\
\hline $\begin{array}{l}\text { Water required for } \\
\text { excretion (if in zero } \\
\mathrm{N} \text { balance) } \\
(\mathrm{mmol} / 2000 \mathrm{kcal})\end{array}$ & 1260 & 860 & 430 & 628 & 1000 & 874 \\
\hline $\begin{array}{l}\text { Sodium equivalent } \\
\text { (m-equiv. } 2000 / \mathrm{kcal} \text { ) }\end{array}$ & 79 & 50 & 32 & $<5$ & 72 & 48 \\
\hline
\end{tabular}

Fig. 1. Comparative values of commercially available tube feeds; Complan, Glaxo Ltd; Forceval, Unigreg, Wimbledon; CIBF, Carnation Instant Breakfast Food, Carnation Foods Co. Ltd; Nutrament, Mead Johnson; AMH std, Atkinson Morley's Hospital standard; CHO, carbohydrate; PROT, protein.

The block diagrams at the top of the diagram show, for each preparation, the proportion of calories that come from protein, carbohydrate and fat. Complan (Glaxo Ltd) is shown on the extreme left, followed by the modification of Complan that we use for our standard tube feed and which $I$ will describe in more detail later. Next comes our low protein modification of Complan, followed by three other easily obtainable commercial preparations.

On the next line are shown the non-protein kcal/g nitrogen present in each of these preparations when made up. This is important in relation to the utilization of the protein fed.

The osmotic load that the kidneys must handle for every $2000 \mathrm{kcal}$ fed has been calculated, assuming that the patient is in zero $\mathrm{N}$ balance. In practice, of course, there will be an additional load during the period of negative balance and a decrease 
when the balance reverses and becomes positive. The size of the blocks enclosing these figures represents the relative volumes of water required for the excretion of the products from these different feeds.

On the next line are shown m-equiv. of sodium derived from each $2000 \mathrm{kcal}$ of feed. Sodium content need present no problem since it is easy enough to add additional salt when the content of the feed is not high enough, and it is possible to obtain a low sodium feed using Forceval (Unigreg, Wimbledon).

Assuming a day's ration of about $2000 \mathrm{kcal}$; vitamin and mineral requirements, with the exception of iron, are covered by all these commercial preparations. Vitamin supplementation may be necessary when feeds are reduced or modified or it is considered that additional vitamin $\mathrm{C}$ is needed. None of the preparations contains adequate iron for long-term maintenance as they are all based on milk protein. Addition of iron must always be considered, especially if there has been blood loss.

In the unconscious patient there is an increased mobilization of calcium from bones. With the milk-based preparations, calcium requirement is already more than adequately covered, but hypercalcuria and calculus formation has been reported in some long-term cases.

Ideally, feeds should be prepared under controlled conditions in a diet kitchen. Very little space or equipment is, in fact, required, and the work can be done by a diet cook with a minimum of training. However, in many units feeds will have to be prepared by the nursing staff on the unit, and it is therefore an advantage if a readily available and easily prepared commercial preparation can be used. Nevertheless, it is not enough just to use the commercial preparation alone to provide the calorie requirements. This was at one time, in fact, our practice using Complan; this sometimes gave rise to troubles.

Solute-loading hypertonicity occurs when the body water becomes overloaded with substances in solution which the kidneys are unable to excrete because of insufficient water (Moore, 1959). It is the size of the load to be cleared that is the important factor. The normal kidney is able to concentrate the urine to contain about $1300 \mathrm{~m}-0 \mathrm{sm} / 1$. This maximum efficiency is not found in these patients so that the $1260 \mathrm{~m}$-osm from $2000 \mathrm{kcal}$ of Complan is going to be excreted in a urine volume of somewhere between $\mathrm{I}$ and $2 \mathrm{l}$.

Fig. 2 shows what may happen when the diet contains more protein and salts than the particular patient can manage when not able to regulate her own fluid intake. This was a lady of 69 who arrived $2 \mathrm{~d}$ after a coma-producing subarachnoid haemorrhage. On admission, she was still unconscious and with a normal blood pressure. Surgical evacuation of a cerebellar haematoma was carried out and she was started on tube feeding as she remained in coma. Though her blood urea when first estimated was $127 \mathrm{mg} / 100 \mathrm{ml}$, she was started on full strength Complan feeds. Her fluid intake was increased to $31 / d$, all by nasogastric tube since she was absorbing satisfactorily, but her plasma osmolality and sodium continued to rise as did her blood urea and blood sugar until the feed was modified so that it contained less Complan. The total calorie value was made up by the addition of extra fat and carbohydrate. 


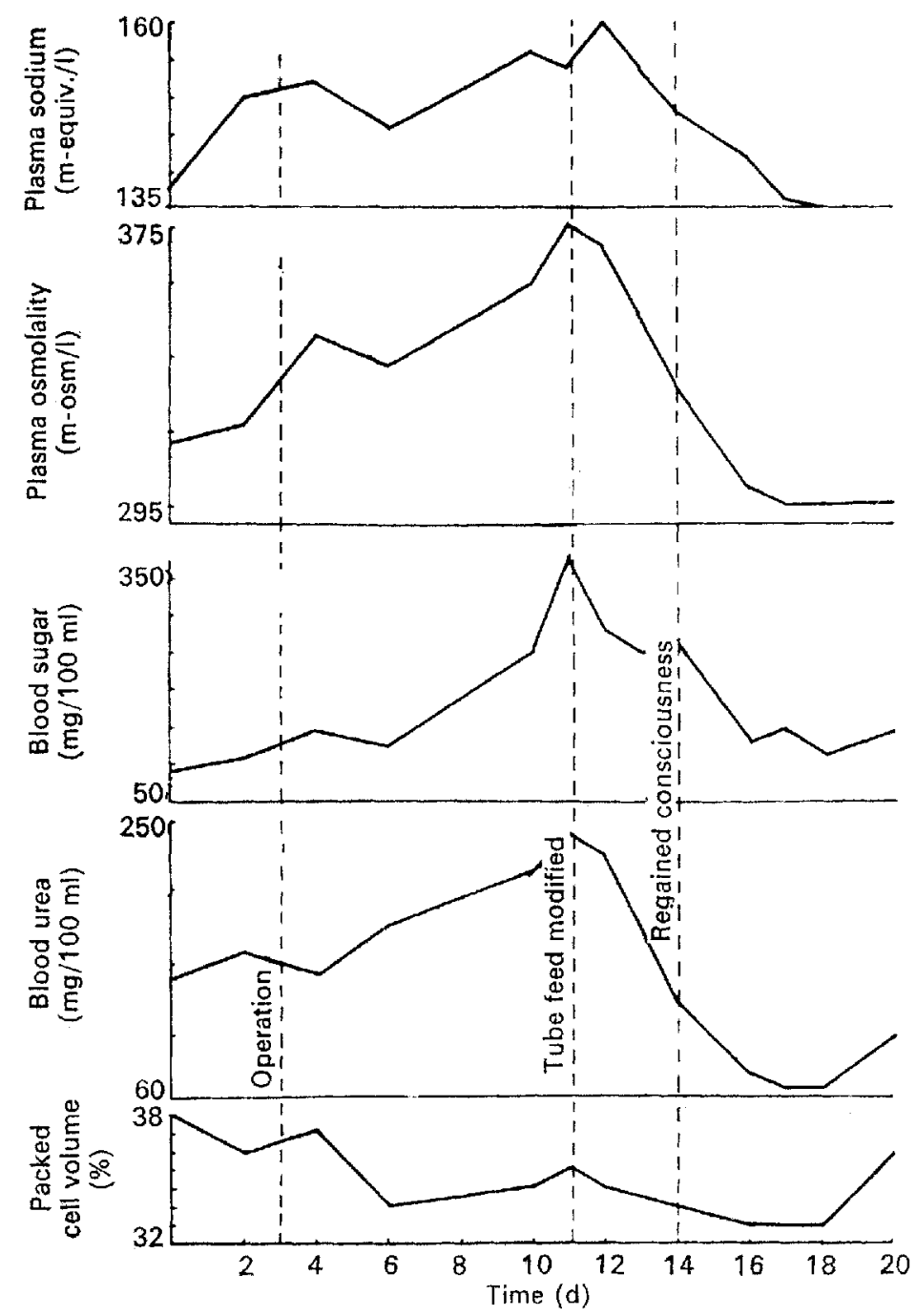

Fig. 2. The effect of solute-loading hypertonicity in one patient.

After this, her blood chemistry returned towards normal, and she regained consciousness and began to respond verbally.

Another problem is that of osmotic diarrhoea caused by feeding hypertonic mixtures too high in sugars or electrolytes (Masterton, Dudley \& MacRae, 1963). Diluting the mixture so that the carbohydrate content does not exceed $10 \%(\mathrm{w} / \mathrm{v})$ may stop this. Thus, when giving a volume of 2.51 in $24 \mathrm{~h}$, up to $25^{\circ} \mathrm{g}$ carbohydrate will generally be tolerated. Replacing sugars with a carbohydrate of low osmolality such as Caloreen (Scientific Hospital Supplies, $3^{8}$ Queensland Street, Liverpool) may help; so may thickening the feed with methylcellulose or, more simply, with cornflour.

Diarrhoea may also be due to lactose intolerance as pointed out by Peaston (1966). 
In our experience, non-absorption by the stomach or diarrhoea usually arise from poor management at the institution of feeding. It is important to remember that the stomach may have been empty for some considerable time, and the full feed cannot be achieved for some days. In the early stages, the fluid volume given must be small, of dilute strength and not ice-cold out of a refrigerator. A standard 24-h ration of the modified Complan used at Atkinson Morley's Hospital uses Complan equivalent to $105 \mathrm{~g}$ protein with added glucose and Prosparol (British Drug Houses Ltd) to make up to $2200 \mathrm{kcal}$. This is mixed with $1800 \mathrm{ml}$ water and given according to a 3 -hourly plan with additional water. Six formula feeds and two of water only are given in the $24 \mathrm{~h}$ with a total fluid intake of 2.51 . Rehydration must be carefully controlled because it is important at this stage not to over-hydrate or cause water intoxication (Lewin, 1959) which can lead to cerebral swelling and cerebral oedema. The brain cells are extremely sensitive to water and the influence of the osmolality of the body fluids.

The detailed schedule allows for different protein and sodium contents and for variation in water intake (Buckell, 1968 ).

Feeding starts with the passage of a nasogastric tube and aspiration of the stomach. $30 \mathrm{ml}$ of water is put down the tube, and $\mathrm{I} h$ later the stomach is aspirated. If the first lot of water has been absorbed, another $30 \mathrm{ml}$ is given and the stomach again aspirated after a further hour; $\mathrm{I} 20 \mathrm{ml}$ of $5 \%$ glucose is then given. Three $\mathrm{h}$ later the stomach is aspirated to see if this has been accepted, and the procedure is repeated before every feed. If a feed is not absorbed, a return is made to a weaker feed. If all is going well, the schedule works up through half- and full-strength milk and then on to the Complan mixture.

In assessing the adequacy of tube feeding we are guided by the general appearance of the patient. Good healing following surgery and the prevention of bed sores in the long-term unconscious patient are also an indication. The satisfactory laboratory results for blood urea, electrolytes and haemoglobin together with the maintenance of weight and fluid balance will indicate that the patient is being adequately fed and hydrated. At Atkinson Morley's, as in any other specialized or intensive care unit, it is essential that there is accurate fluid-charting. Recording of laboratory results and details of the feeding schedule are required for the benefit of the medical and nursing staff, dietitian and anyone else involved in the patients' care.

It is difficult with the unconscious patient to do routine weight checks unless a weigh-bed is available. However, we have at Atkinson Morley's devised a method of weighing the patient for the purpose of balance studies or where clinical problems arise.

In conclusion, the points that must be taken into account when feeding the unconscious patient are the provision of adequate fluid to prevent dehydration and solute-loading from hypertonic feedings. An adequate calorie: $\mathrm{N}$ ratio to cover the patient's requirements must be ensured. Osmotic disturbances are unlikely to occur where balanced feeds are given, and can generally be easily corrected by modifying the feeds. A carefully graded schedule must be followed when feeds first commence. We have shown how easily suitable feeds can be provided by using 
the commercial preparations available. It must always be remembered that these unconscious patients are utterly dependent on the observations of those looking after them for their maintenance and care.

Dr Monamy Buckell wishes to thank the Medical Research Council for a grant to Atkinson Morley's Hospital.

\section{REFERENCES}

Buckell, M. (1968). Nutrition, Lond. 22, i io.

Cuthbertson, D. P. \& Tilstone, W. J. (1969). Adv. clin. Med. 12, 1.

Lewin, W. (1959). Proc. R, Soc. Med. 52, 874 .

Masterton, J. P., Dudley, H. A. F. \& MacRae, S. (I963). Br. med. F. ii, gog.

Moore, F. D. (1959). Metabolic Care of the Surgical Patient. Philadelphia and London: Saunders.

Peaston, M. J. T. (1966). Br. med. F. ii, I367. 